\title{
Effect of School-Based Social Skills Training Program on Peer Relationships: Preliminary Study
}

\author{
Hong-Shik Roh', Jung-Uk Shin', Jae-Woo Lee', Yeon-Woo Lee ${ }^{2}$, Tae-Won Kim², \\ Ji-Young Kim², Mi-Ri Park ${ }^{2}$, Gang-Sik Song ${ }^{2}$, and Sang Soo Seo ${ }^{3}$ \\ ${ }^{1}$ Department of Psychiatry, Bugok National Hospital, Changnyeong, Korea \\ ${ }^{2}$ Department of Child and Adolescent Mental Health Promotion, Bugok National Hospital, Changnyeong, Korea \\ ${ }^{3}$ Department of Child and Adolescent Psychiatry, Bugok National Hospital, Changnyeong, Korea
}

\begin{abstract}
Objectives: The aim of this study was to evaluate the effect of a school-based social skills training program on peer relationships in children and adolescents and to assess the plan for effective school-based mental health services.

Methods: The Child and Adolescent Mental Health Promotion Team of Bugok National Hospital conducted 7-sessioned school-based social skills training for elementary and middle school students $(n=90)$. Changes in peer relationships were evaluated before and after application of the program using a name generator question.

Results: The social skills training program increased peer relations, indicating significant changes in social network indices.

Conclusion: The social skills training program positively influenced peer relationships. The school-based social skills training program can be expected to have positive effects on school-based mental health services. Future investigation is needed to validate the long term effects of this program.
\end{abstract}

Key Words: Social skills training; Peer relationship; School-based mental health promotion.

Received: June 2, 2017 / Revision: September 22, 2017 / Accepted: October 18, 2017

Address for correspondence: Sang Soo Seo, Department of Child and Adolescent Psychiatry, Bugok National Hospital, 145 Bugok-ro, Bugok-myeon, Changnyeong 50365, Korea

Tel: +82-55-520-2509, Fax: +82-55-536-6444, E-mail: sss2913@korea.com

\section{INTRODUCTION}

Children and adolescents build social relationships and carry out emotional development through peer relationships. ${ }^{1)}$ Negative peer-relationship experienced by children and adolescents can easily frustrate them in stressful situations, can create negative self-conception, and are highly related to school maladjustment. Further, they can lead to the growth of delinquent behavior and mental health problems. Therefore, peer relationship in childhood and adolescence is a necessary process for successful social adjustment in adulthood and formation of healthy interpersonal relationships. ${ }^{2)}$ Parents and family play an important role in the early school-age during childhood and adolescence, but peer relationships become more important from the late schoolage and influence the individual's self-evaluation and selfimage. ${ }^{3)}$ Children and adolescents who are of the school-going age can establish new relationships with teachers along with peer relationships, and teacher-student relationships could

This is an Open Access article distributed under the terms of the Creative Commons Attribution Non-Commercial License (http://creativecommons.org/licenses/by-nc/4.0) which permits unrestricted non-commercial use, distribution, and reproduction in any medium, provided the original work is properly cited. also affect their behavior, self-confidence, and efficacy. ${ }^{4)}$ However, children and adolescents are more likely to be influenced by peer relationships than by teacher-student relationships. ${ }^{5-7)}$ Therefore, supportive peer relationships have the effect of reducing anxiety, depression, and subjective stress index compared to relationships with family and teachers as well as of increasing prosocial behavior and self-esteem. ${ }^{8)}$ The formation of peer relationships among children and adolescents in school is initially influenced by peer group's personality, physical attractiveness, and similarity, but student's interactions during the curriculum also contribute to the change in peer relationships.9) At this time, educational program offered by the school can serve as a mediator of peer interactions forming the social attitude and personality of children and adolescents. ${ }^{10,11)}$ Therefore, various interactions and educational experiences through school-based educational programs can help to change the formation of positive interpersonal relationships. ${ }^{12)}$

In Korea, school-based mental health promotion projects are being implemented to ensure optimal child and adolescent mental health services due to the importance of mental health problems among children and adolescents. ${ }^{13)}$ Schools 
is a good place to implement mental health promotion projects for children and adolescents because most children and adolescents spend much time attending school, and school not only is the institution that function as social educator for children and adolescents but also has a large impact on families and communities. In addition, school is also a place for children and adolescents to learn new things. ${ }^{14)}$ Schoolbased social skills training program in previous studies ${ }^{15-17)}$ has focused on appropriate expression of emotions and acquisition of social skills such as understanding and expressing one's feelings to others as well as resolving conflicts in a social way. Prosocial behavior and perceptions about mental health of students were significantly improved after social skills training program and mental health awareness improvement program of Seoul National University Hospital. ${ }^{18)}$ In addition, school-based social skills training program has been reported to be able to significantly lower the degree of alexithymic tendency among children and adolescents. ${ }^{19)}$

School-based mental health promotion emphasizes the relationships of all students as a group rather than that of students as individuals. ${ }^{18,19)}$ In particular, school maladjustment is often accompanied by alienation of relationships, and the isolation of the networks surrounding vulnerable students has an adverse effect on the mental health promotion of not an individual student alone but all the students. ${ }^{20)}$ However, the effects of school-based mental health promotion programs on peer relationships have not been sufficiently studied.

This study examines the effects of school-based social skills training program on peer relationships and seeks ways for better mental health promotion programs.

\section{METHODS}

\section{Subjects and procedures}

We organized the 7th session of the "Social Skills Training Program" from May to August, 2016, targeting students enrolled in Bugok Elementary School and Middle School that entered an agreement with Bugok National Hospital Mental Health Promotion Division and investigated changes in peer relationships before and after application of the program. The peer relationship survey was conducted by the researcher after explaining the purpose of the research and the method of answering the questionnaire; data was collected using name generator question (NGQ). Before proceeding with the program, we distributed the program guide and parental permission form to parents for correspondence and proceeded with the program after collecting them, written informed consent. This prospective study was approved by the Bugok National Hospital Clinical Research Ethics Committee (IRB No. 5-009). Bugok Elementary School and Bugok Middle School were small schools with 70 and 56 students, respectively, and school children in the lower grades who had troubles understanding the research content were not made to answer the questionnaire.

\section{Program composition and progress}

"Social Skills Training Program" was held for seven sessions, one session per week, 40 minutes per session. Each program was used by modifying and supplementing the social skills development program ${ }^{21)}$ developed by Daegu Metropolitan Office of Education in accordance with the state

Table 1. The content of the social skills training program (elementary school)

\begin{tabular}{cll}
\hline Session & \multicolumn{1}{c}{ Subject } & Contents \\
\hline 1 & Let's get another your name & To give a nickname, To Introduce myself \\
2 & Let's talk with your friends & To Introduce my best friend \\
4 & I like this kind of friend & Good friends \\
5 & What kind of friend are you? & Telationship with my friends \\
6 & Let's express your mind to friends yourself, communication & Effective listening \\
7 & Let's listen to your friends & Empathy, read your mind \\
\hline
\end{tabular}

Table 2. The content of the social skills training program (middle school)

\begin{tabular}{cll}
\hline Session & \multicolumn{1}{c}{ Subject } & \multicolumn{1}{c}{ Contents } \\
\hline 1 & Who are you? & To give a nickname, to Introduce myself \\
3 & To give my mind for present & To make group painting \\
4 & Listening & Communication game \\
5 & Would you like to listen to my story? & Role-playing \\
6 & How to reconcile with a friend I & Quiz of effective apology want \\
7 & How to reconcile with a friend II & Rolling paper
\end{tabular}


of education (Table 1 and 2). We implemented the original social skills development program for middle school students and made the vocabulary used in the activity contents easier for elementary students through a meeting with the teachers in charge. Program was implemented among elementary and middle school students, and the teachers in charge of each class, three mental health specialists, two child and adolescent mental health promotion team members participated in the course of the program.

\section{Measures}

We used NGQ to analyze the effects of school-based social skills training program on the peer relationships. NGQ is a question form designed to nominate the name of the members who correspond to each question. The data generated through the questionnaire is formulated into matrix-related relationship variables for social network analysis. ${ }^{22}$ Specific questions asked as to whom the target students would like to invite, such as "You have your birthday party at home today, who do you want to take with you?"

Such method of measuring social skills is a way of describing the social relations devised by Moreno. ${ }^{23)}$ At the time of the initial design, it started with the question "Choose a friend you want to sit with," asked to students from kindergarten to middle school. Currently, it is being developed as a social network analysis, which helps to understand the types of peer relations and the structure of group relations. ${ }^{22)}$

Social network analysis is a methodology for analyzing its topological structure, diffusion, and evolution process quantitatively by modeling the relationship between individuals and groups as node-link. ${ }^{24)}$ The techniques that are widely used in social network analysis are centrality, density, and centralization. ${ }^{25)}$ Among them, the method of measuring centrality is as follows.

\section{Degree centrality}

It is obtained as the sum of nodes directly connected to one node in the network and indicates the degree of connection with other nodes. It quantifies the degree to which the node is located at the center, based on how many nodes are related to one node. The more the number of nodes that are connected to one node, the higher the degree centrality.

\section{Closeness centrality}

Closeness centrality is also called adjacency centrality and determines how close one node is to another node, that is, a method of measuring the centrality based on the distance between two nodes. It measures centrality by summing up the distances between all indirectly connected nodes, taken two at a time, unlike the degree centrality.
For example, assuming that one person meets everyone in the group, it is possible to know everyone indirectly through the person he knows, although he does not directly know everyone in the group. At this time, closeness centrality is the closest way to get to know everyone. Closeness centrality is defined as the sum of minimum steps required from one node to another node. The higher the closeness centrality, the closer to the center of the network.

\section{Betweenness centrality}

Betweenness centrality is a method of measuring centrality as the degree of mediator or arbitrator that one node plays in the network. For example, assuming that there are three people $A, B$, and $C$, if $A$ and $B$ can only relate through $C, C$ acts as a "broker" to potentially control communication between the other two. In other words, the more centrally one node is located on the largest route between the other nodes in the network, the higher the betweenness centrality of the node is. The higher the betweenness centrality is, the more likely the node is to affect the flow of communication in the network.

\section{Eigenvector centrality}

It is a method to predict the centrality of the node by weighting the importance of the node connected to another node. Eigenvector indicates how many nodes are directly connected to one node and the greater the number, the higher the eigenvector. Also, the more the connection with the higherranking people, the higher the eigenvector. For example, eigenvector of connection with people who are connected to many influential people is higher than that of connection with those who are not. Eigenvector centrality is determined by combining the influence of one's own degree centrality and influence of others connected with oneself.

\section{Data analysis}

Social relationships of students are measured by answering NGQ before and after application of the program to examine the effect of school-based social skills training program on peer relationships and we performed social network analysis with the collected data using R-3.3.2 (R Foundation for Statistical Computing, Vienna, Austria). For the statistics calculated through social network analysis, we verified the significance by conducting the corresponding paired t-test, and verified the significance of peer relationships through the 2-tailed permutation test for randomly regrouped, calculating repeatedly 100000 times. Statistical significance level was 0.05 . 


\section{RESULTS}

\section{Demographic characteristics}

A total of 90 students participated in the social skills training program, including 47 male students and 43 female students. There were a total of 34 high-grade elementary school students aged 10-12, including 19 male students and $15 \mathrm{fe}$ male students. There were a total of 56 middle school students aged 13-15, including 28 male students and 28 female students (Table 3).

Table 3. Demographic information for students of sample $(n=90)$

\begin{tabular}{clll}
\hline Age & Male & Female & Total $(\%)$ \\
\hline $10-12$ & 19 & 15 & $34(34)$ \\
$13-15$ & 28 & 28 & $56(56)$ \\
Total $(\%)$ & $47(52.2)$ & $43(47.8)$ & $90(100)$ \\
\hline
\end{tabular}

\section{Peer relationship analysis}

\section{Elementary school students}

The structural form of peer relationship before and after application of the social skills training program is shown in Figs. 1 and 2. The node or one circle represents one student and the size of the circle indicates the size of the node. The larger the circle, the more active the relationship with other students, each line represents a peer relationship. The structural characteristics of elementary school students' peer relationships before and after application of the social skills training program were that students who did not have peer relationships before the program were observed and students who did not have peer relationships were not observed after the program. The density of peer relationships before the application of the program was 0.176471 , and the density of peer relationships after the application of the program was 0.180036 . After implementing a 2-tailed permutation test between the two groups before and after application of

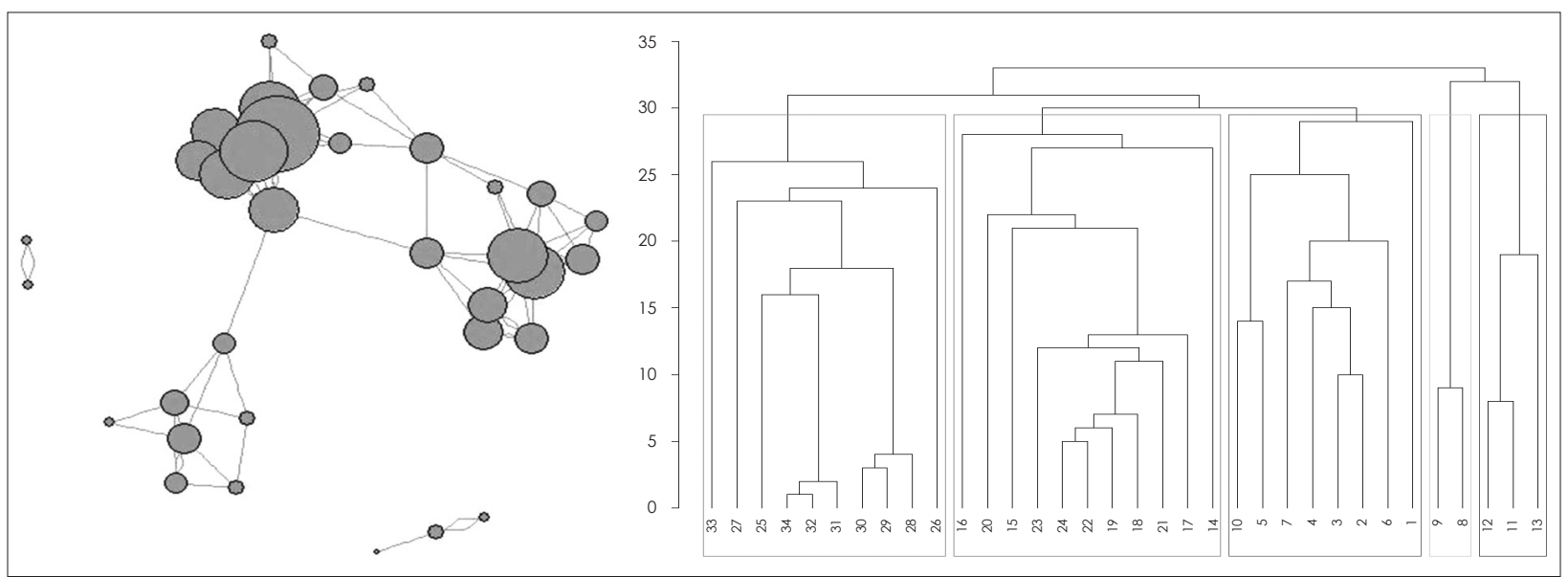

Fig. 1. Social network of elementary school students before the application of the program $(n=34)$.

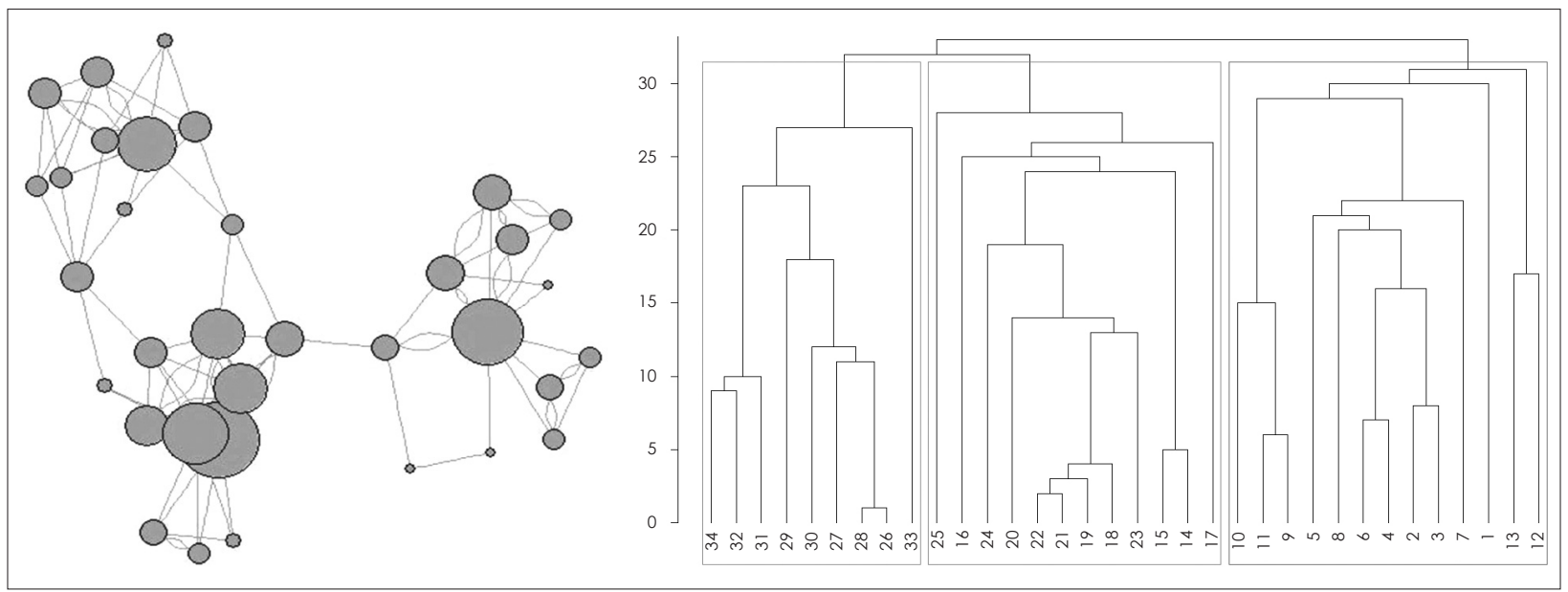

Fig. 2. Social network of elementary school students after the application of the program $(n=34)$. 


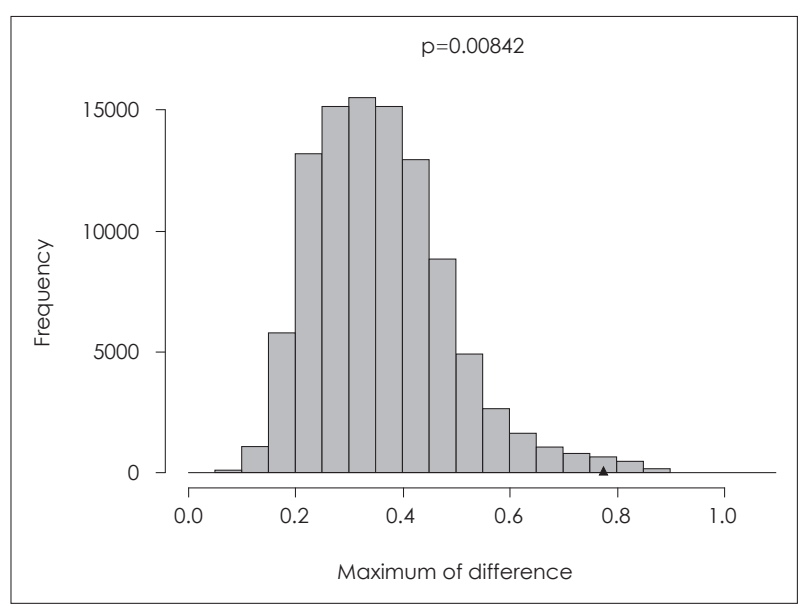

Fig. 3. Reference distributions of test statistics based on the elementary school students for the application of the program $(n=34)$. The triangle indicates the test statistic based on the observed data.

the program, there was a significant difference in the degree of peer relationships ( $\mathrm{p}=0.00842$ ) (Fig. 3). The density indicates the degree of connectivity in the overall relationship, and the increase in density indicates that the cohesion of the whole group has increased. This is the same as previous research showing that social skills training program increases group cohesiveness. ${ }^{19)}$

Table 4 illustrates the statistics showing the centrality of social network analysis of all elementary school students. Each is a measurement value of centrality, indicating degree centrality, closeness centrality, betweenness centrality, and eigenvector centrality. The closeness centrality in the degree of peer relationships between elementary school students before and after the application of the social skills training program changed from $0.0035 \pm 0.0012$ to $0.0092 \pm 0.0015$ ( $\mathrm{t}=-23.970$, $\mathrm{p}=0.0001$ ), and betweenness centrality changed significantly from $23.0588 \pm 45.0152$ to $39.0000 \pm 70.6584(\mathrm{t}=-2.239, \mathrm{p}=$ 0.032 ). There was no significant change in the degree centrality and eigenvector centrality (Table 5).

\section{Middle school students}

The structural form of peer relationships before and after middle school students' participation in social skills training program is shown in Figs. 4 and 5. The density of peer relationships before application of the program was 0.16604 and the density of peer relationships after application of the program was 0.218045 . As a result of implementing 2-tailed permutation test between peer relations, there was a significant difference in peer relationships $(\mathrm{p}=0.00862)$ (Fig. 6). The structural characteristics of the middle school students' peer relationships before and after application of the social skills training program show that middle school students are closely related by each grade, unlike elementary school students who were divided into five groups before the program ( $\mathrm{p}=0.019)$. In addition, it can be seen that the level has been higher after application of the program. Unlike elementary school students who were mentioned earlier, students who did not have peer relationships were not observed.

Table 6 shows statistics, indicating centrality of social network analysis of all middle school students. The degree centrality in peer relationships before and after application of the program changed from $9.34 \pm 5.779$ to $12.16 \pm 9.069(\mathrm{t}=-2.088$, $\mathrm{p}=0.041$ ), and there was a significant change in closeness centrality, that is, from $0.0062 \pm 0.0009$ to $0.0058 \pm 0.0010$ ( $\mathrm{t}=$ $2.407, \mathrm{p}=0.019)$. There was no significant change in betweenness centrality and eigenvector centrality (Table 7).

\section{Male and female students}

The density of peer relationships before application of the social skills training program for male students in elementary school and middle school was 0.043626 and density of peer relationships after application of the program was 0.0471915 . There was a significant difference in the degree of peer relationships after implementing 2-tailed permutation test between peer relationships before and after application of the program ( $\mathrm{p}=0.01287$ ) (Fig. 7).

Table 8 shows the statistical significance of each value showing the centrality of social network analysis through paired t-test of all male students in elementary school and middle school. As a result, there was a significant change in closeness centrality, that is, from $0.0068 \pm 0.0002$ to $0.0049 \pm 0.0002$ $(t=7.2620, p=0.001)$ in the degree of male peer relations before and after application of the social skills training program, and there was no significant change in degree centrality, betweenness centrality, and eigenvector centrality.

The density of peer relationships before application of the social skills training program for female students in elementary school and middle school was 0.067719 and the density of peer relationships after application of the program was 0.086808 . There was a statistically significant difference $(\mathrm{p}=$ 0.00011) (Fig. 7).

Table 8 shows the statistical significance of each value indicating the centrality of the social network analysis through the paired $t$-test of all female students in elementary school and middle school. As a result, there was a significant change in closeness centrality, that is, from $0.0049 \pm 0.0004$ to $0.0052 \pm$ $0.0003(\mathrm{t}=-4.413, \mathrm{p}=0.001)$, in the degree of peer relationships before and after application of the social skills training program. There was no significant change in degree centrality, betweenness centrality, and eigenvector centrality. 
Table 4. Node-level calculations of elementary school students before and after the application of the program $(n=34)$

\begin{tabular}{|c|c|c|c|c|c|c|c|c|}
\hline & \multicolumn{4}{|c|}{ Pre } & \multicolumn{4}{|c|}{ Post } \\
\hline & Degree & Closeness & Betweenness & Eigenvector & Degree & Closeness & Betweenness & Eigenvector \\
\hline 1 & 4 & 0.003509 & 0.333333 & 0.003259 & 6 & 0.007692 & 0.142857 & 0.010742 \\
\hline 2 & 6 & 0.003831 & 40.333333 & 0.009524 & 7 & 0.007692 & 0.571429 & 0.010569 \\
\hline 3 & 2 & 0.003497 & 0 & 0.002026 & 2 & 0.007576 & 0 & 0.004799 \\
\hline 4 & 5 & 0.003831 & 21.333333 & 0.009820 & 13 & 0.009901 & 184.059524 & 0.025648 \\
\hline 5 & 2 & 0.000918 & 0 & 0 & 2 & 0.008621 & 7.666667 & 0.007915 \\
\hline 6 & 2 & 0.000918 & 0 & 0 & 2 & 0.007634 & 2.402381 & 0.003749 \\
\hline 7 & 4 & 0.004149 & 132.333333 & 0.070314 & 5 & 0.011628 & 248.597619 & 0.067120 \\
\hline 8 & 3 & 0.003509 & 0 & 0.002243 & 4 & 0.007634 & 0 & 0.006425 \\
\hline 9 & 3 & 0.003802 & 11.833333 & 0.008629 & 7 & 0.009434 & 25.559524 & 0.017322 \\
\hline 10 & 2 & 0.000946 & 0 & 0 & 5 & 0.007634 & 0 & 0.004850 \\
\hline 11 & 1 & 0.000946 & 0 & 0 & 4 & 0.007634 & 0 & 0.004444 \\
\hline 12 & 3 & 0.000947 & 1 & 0 & 4 & 0.007634 & 0 & 0.004444 \\
\hline 13 & 3 & 0.003891 & 0.000000 & 0.212680 & 5 & 0.008621 & 0.500000 & 0.288087 \\
\hline 14 & 3 & 0.004049 & 4.244705 & 0.190407 & 3 & 0.008547 & 0 & 0.234503 \\
\hline 15 & 11 & 0.004219 & 18.677123 & 0.722669 & 3 & 0.010000 & 20.067491 & 0.211847 \\
\hline 16 & 5 & 0.004082 & 14.793740 & 0.307740 & 4 & 0.008547 & 0 & 0.266678 \\
\hline 17 & 9 & 0.004098 & 0 & 0.795419 & 8 & 0.009615 & 0 & 0.738759 \\
\hline 18 & 15 & 0.004219 & 33.203313 & 1 & 15 & 0.011494 & 82.698932 & 1 \\
\hline 19 & 4 & 0.004065 & 7.436597 & 0.285462 & 12 & 0.011494 & 47.239957 & 0.811569 \\
\hline 20 & 8 & 0.004098 & 0 & 0.700603 & 6 & 0.010417 & 37.663595 & 0.479928 \\
\hline 21 & 10 & 0.004098 & 0 & 0.856094 & 10 & 0.011765 & 30.280345 & 0.800817 \\
\hline 22 & 9 & 0.004425 & 197.774958 & 0.643298 & 7 & 0.013158 & 266.588173 & 0.524431 \\
\hline 23 & 12 & 0.004184 & 9.400450 & 0.907468 & 10 & 0.010989 & 7.113889 & 0.860727 \\
\hline 24 & 4 & 0.003802 & 0 & 0.010096 & 11 & 0.010000 & 96.214594 & 0.037043 \\
\hline 25 & 11 & 0.004098 & 31.369863 & 0.030677 & 6 & 0.008000 & 1.500000 & 0.017166 \\
\hline 26 & 6 & 0.003802 & 0 & 0.015913 & 6 & 0.008000 & 1.166667 & 0.016280 \\
\hline 27 & 11 & 0.004098 & 31.369863 & 0.030677 & 4 & 0.008547 & 5.442130 & 0.017392 \\
\hline 28 & 5 & 0.003922 & 16.434632 & 0.019113 & 4 & 0.008547 & 5.442130 & 0.017392 \\
\hline 29 & 7 & 0.004032 & 6.085714 & 0.024307 & 5 & 0.008621 & 9.625397 & 0.019728 \\
\hline 30 & 7 & 0.004032 & 6.085714 & 0.024307 & 3 & 0.007874 & 0 & 0.009529 \\
\hline 31 & 3 & 0.003891 & 3.871429 & 0.016389 & 3 & 0.008475 & 2.319048 & 0.016845 \\
\hline 32 & 6 & 0.004348 & 138.139244 & 0.088865 & 4 & 0.011628 & 152.945105 & 0.155338 \\
\hline 33 & 6 & 0.003731 & 0 & 0.016611 & 6 & 0.009709 & 33.554321 & 0.028553 \\
\hline 34 & 6 & 0.004167 & 57.112654 & 0.095108 & 6 & 0.009259 & 56.638228 & 0.085231 \\
\hline Mean & 5.82 & 0.003534 & 23.058824 & 0.208815 & 5.94 & 0.009236 & 39.000000 & 0.200173 \\
\hline
\end{tabular}

Table 5. Changes in centality analysis variables of elementary school students before and after the application of the program $(n=34)$

\begin{tabular}{lccc}
\hline \multirow{2}{*}{ Variables } & Pre & Post & $\dagger$ \\
\cline { 2 - 3 } Degree & Mean (SD) & Mean (SD) & -0.197 \\
Closeness & $5.82(3.451)$ & $5.94(3.237)$ & $-23.970^{\dagger}$ \\
Betweenness & $0.0035(0.0012)$ & $0.0092(0.0015)$ & $-2.239 *$ \\
Eigenvector & $23.0588(45.0152)$ & $39.0000(70.6584)$ & 0.367 \\
\hline
\end{tabular}

${ }^{*} p<0.05,{ }^{\dagger} p<0.01$. Betweenness: betweenness centrality, Closeness: closeness centrality, Degree: degree centrality, Eigenvector: eigenvector centrality, SD: standard deviation 


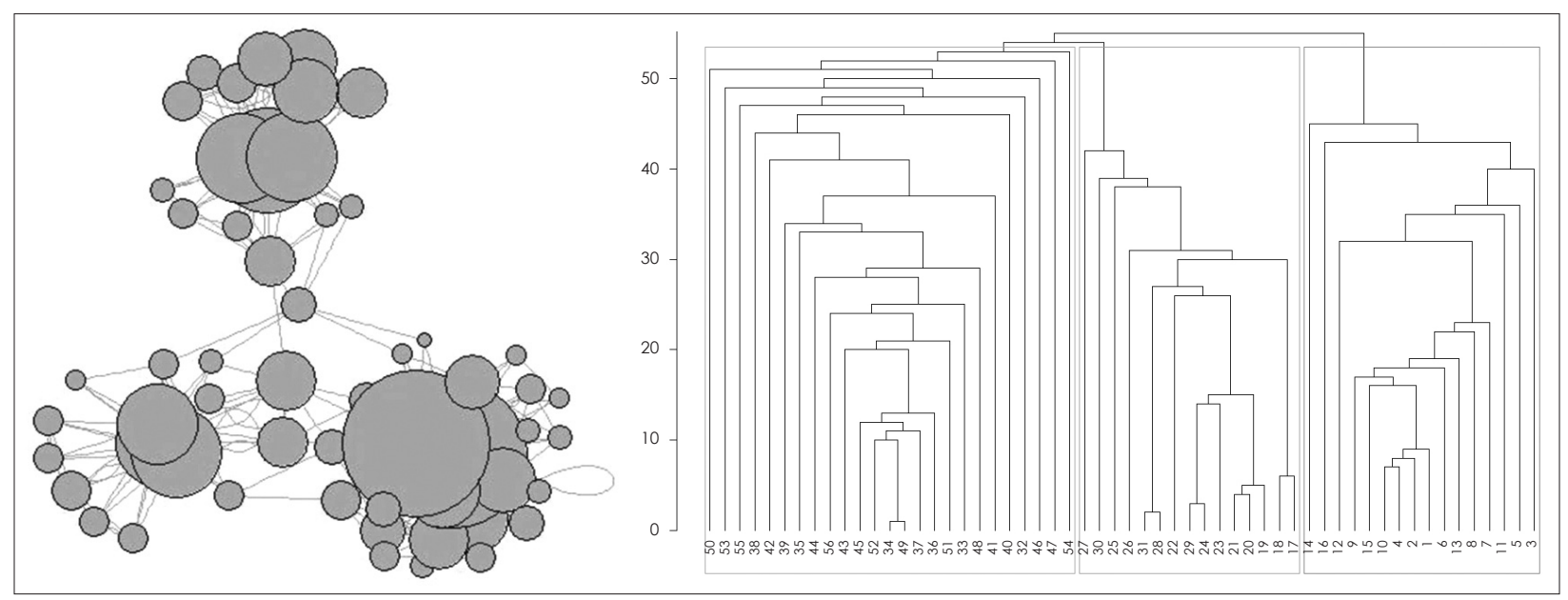

Fig. 4. Social network of middle school students before the application of the program $(n=56)$.

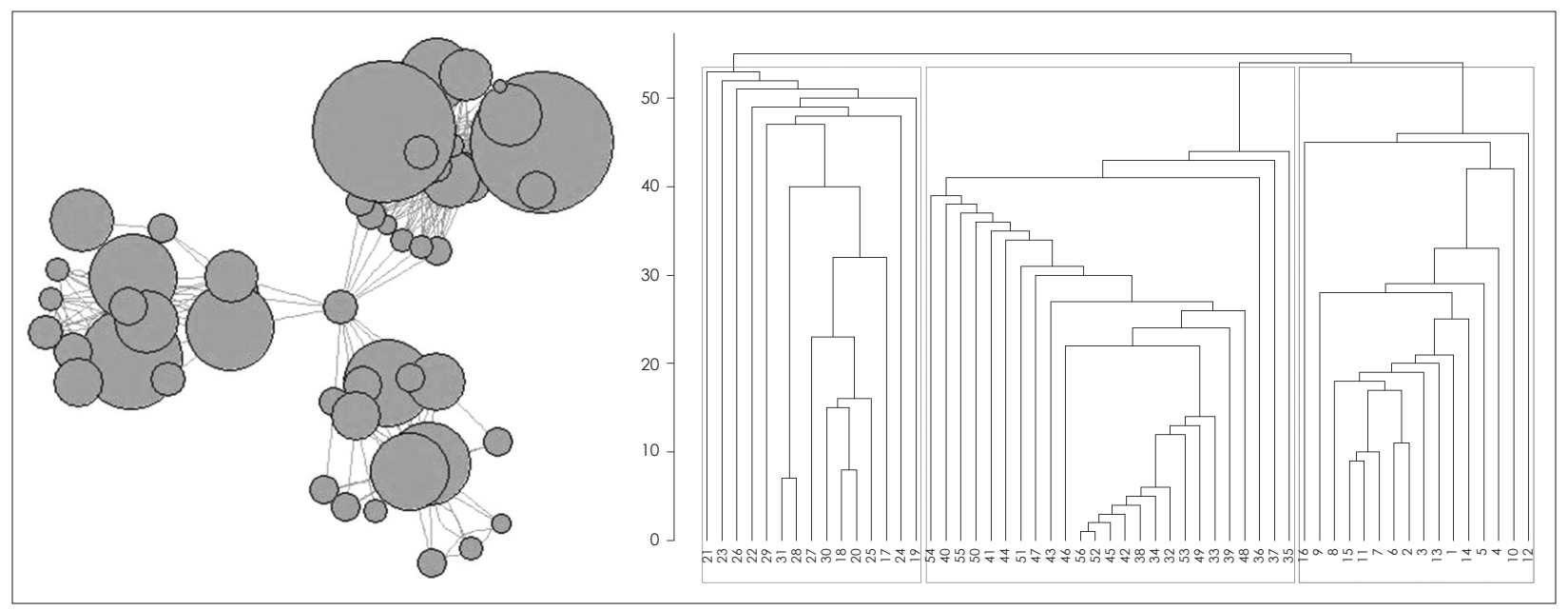

Fig. 5. Social network of middle school students after the application of the program $(n=56)$.

\section{Correlation analysis}

If we look at the correlation between statistics that measure the centrality of social network analysis, there is a correlation among degree centrality, closeness centrality $(\mathrm{p}<0.01)$, betweenness centrality $(\mathrm{p}<0.01)$, and eigenvector centrality $(\mathrm{p}<$ 0.01 ). Further, there is a correlation between closeness centrality and betweenness centrality $(\mathrm{p}<0.01)$, and there is no correlation among eigenvector centrality, closeness centrality, and betweenness centrality (Table 9).

\section{DISCUSSION}

Childhood and adolescence are the times to prepare for the establishment of social skills and self-identity through various experiences. Children and adolescents at this time undergo various changes physically and mentally and their internal problems are exposed, which makes it difficult for them to adapt to social needs. ${ }^{26)}$ Peer relationships during this period are comforting in these conflict situations, but they can be the cause of expressing conflict or can be the target. Individuals who are unable to form appropriate peer relationships at this time are likely to be less able to control their emotions and display problematic behaviors at school. ${ }^{8)}$

As a result of the study, the connectivity of the peer relationships among elementary school students who participated in the social skills training program was increased. Students who did not have peer relationships were observed before application of the program, but student who did not have peer relationships were not observed in the evaluation after application of the program. In particular, the structural point of view, elementary school students seem to have a peer relationship other than the same grade unlike middle school students. As closeness centrality ( $\mathrm{p}=0.0001)$ and betweenness centrality $(\mathrm{p}=0.032)$ significantly increased after application of the social skills training program, it has been observed that social skills training program for school-based mental health 


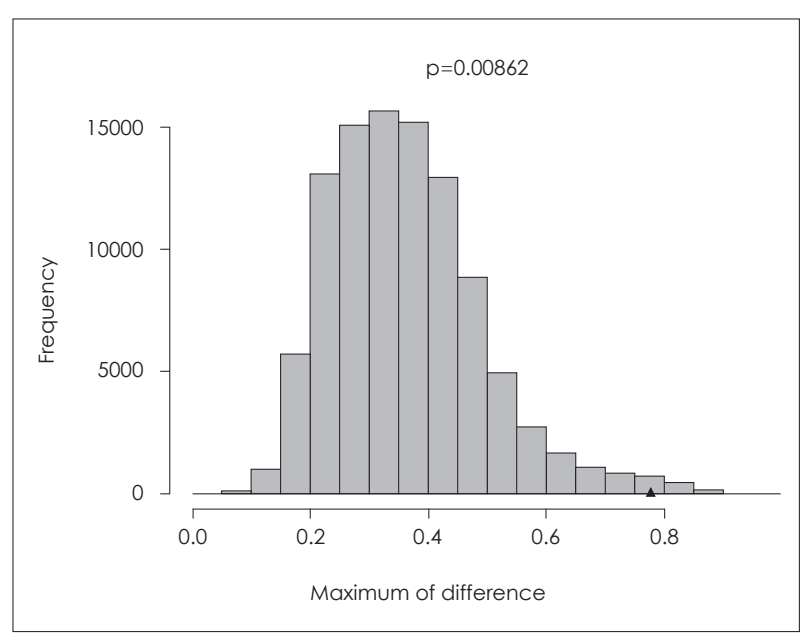

Fig. 6. Reference distributions of test statistics based on the middle school students for the application of the program $(n=56)$. The triangle indicates the test statistic based on the observed data. promotion service can affect peer relationships.

It has been observed that middle school students make peer relationships with students of the same grade unlike elementary school students. It seems that there are less or no peer relationships with other grades (Figs. 4 and 5). Middle school students' school cohesion with the same grade increased after application of the program $(\mathrm{p}=0.00862)$. Before and after application of the program, the degree centrality $(p=0.041)$ of middle school students was significantly increased, but there was no significant difference in betweenness centrality and eigenvector centrality. In addition, closeness centrality $(\mathrm{p}=0.019)$ was significantly decreased before and after application of the program, so it was thought that middle school students' peer relationships were not fixed in this study.

There was a significant difference in the degree of peer relationships among male students before and after application of the social skills training program (male students $\mathrm{p}=0.01287$

Table 6. Node-level calculations of middle school students before and after the application of the program $(n=56)$

\begin{tabular}{|c|c|c|c|c|c|c|c|c|}
\hline & \multicolumn{4}{|c|}{ Pre } & \multicolumn{4}{|c|}{ Post } \\
\hline & Degree & Closeness & Betweenness & Eigenvector & Degree & Closeness & Betweenness & Eigenvector \\
\hline 1 & 21 & 0.006135 & 118.655802 & 1 & 15 & 0.005495 & 24.666346 & 0.000784 \\
\hline 2 & 13 & 0.004762 & 0.671898 & 0.757121 & 6 & 0.004367 & 0 & 0.000386 \\
\hline 3 & 5 & 0.005650 & 0 & 0.282069 & 10 & 0.004425 & 0 & 0.000430 \\
\hline 4 & 10 & 0.004717 & 0 & 0.652680 & 6 & 0.006803 & 149.882600 & 0.005109 \\
\hline 5 & 6 & 0.006098 & 28.850568 & 0.288352 & 19 & 0.005618 & 58.120444 & 0.001418 \\
\hline 6 & 18 & 0.006135 & 131.846134 & 0.844892 & 7 & 0.006849 & 233.234800 & 0.005131 \\
\hline 7 & 7 & 0.004717 & 0 & 0.443201 & 8 & 0.005376 & 2.402778 & 0.000647 \\
\hline 8 & 8 & 0.004717 & 0 & 0.500504 & 12 & 0.004464 & 0.896825 & 0.000524 \\
\hline 9 & 18 & 0.006135 & 88.285007 & 0.869072 & 22 & 0.005618 & 75.747229 & 0.001477 \\
\hline 10 & 13 & 0.004762 & 0.978716 & 0.754608 & 20 & 0.005618 & 67.155738 & 0.001434 \\
\hline 11 & 6 & 0.005814 & 0.478604 & 0.303965 & 10 & 0.005376 & 5.323529 & 0.000976 \\
\hline 12 & 10 & 0.007519 & 459.439209 & 0.414517 & 10 & 0.004425 & 0 & 0.000430 \\
\hline 13 & 8 & 0.004717 & 0 & 0.537884 & 19 & 0.005618 & 58.120444 & 0.001418 \\
\hline 14 & 5 & 0.006061 & 23.169583 & 0.263373 & 7 & 0.004386 & 0 & 0.000404 \\
\hline 15 & 11 & 0.004762 & 0.469877 & 0.667039 & 6 & 0.006803 & 149.882600 & 0.005109 \\
\hline 16 & 5 & 0.006061 & 23.169583 & 0.263373 & 3 & 0.004149 & 0 & 0.000238 \\
\hline 17 & 6 & 0.005208 & 0 & 0.015571 & 4 & 0.006410 & 77 & 0.004968 \\
\hline 18 & 17 & 0.007092 & 91.381967 & 0.043850 & 15 & 0.005348 & 87.833333 & 0.001672 \\
\hline 19 & 18 & 0.007092 & 138.420084 & 0.051975 & 3 & 0.006369 & 35 & 0.004950 \\
\hline 20 & 16 & 0.007092 & 80.988299 & 0.042432 & 16 & 0.005348 & 105.833333 & 0.001682 \\
\hline 21 & 6 & 0.005208 & 0 & 0.015571 & 3 & 0.005051 & 0 & 0.000394 \\
\hline 22 & 8 & 0.005263 & 1 & 0.020083 & 3 & 0.006369 & 35 & 0.004950 \\
\hline 23 & 12 & 0.009174 & 614.737731 & 0.084193 & 4 & 0.006410 & 77 & 0.004968 \\
\hline 24 & 10 & 0.007813 & 106.858544 & 0.051015 & 5 & 0.006452 & 119.333333 & 0.004987 \\
\hline 25 & 6 & 0.006289 & 35.202858 & 0.020550 & 3 & 0.006369 & 35 & 0.004950 \\
\hline 26 & 5 & 0.006849 & 17.128236 & 0.024564 & 3 & 0.005051 & 0 & 0.000395 \\
\hline 27 & 4 & 0.005348 & 0 & 0.013050 & 4 & 0.004167 & 0 & 0.000175 \\
\hline 28 & 6 & 0.005208 & 0 & 0.015571 & 3 & 0.005051 & 0 & 0.000394 \\
\hline 29 & 6 & 0.006579 & 0 & 0.026665 & 3 & 0.005051 & 0 & 0.000395 \\
\hline
\end{tabular}


Table 6. Node-level calculations of middle school students before and after the application of the program $(n=56)(c o n t i n u e d)$

\begin{tabular}{|c|c|c|c|c|c|c|c|c|}
\hline & \multicolumn{4}{|c|}{ Pre } & \multicolumn{4}{|c|}{ Post } \\
\hline & Degree & Closeness & Betweenness & Eigenvector & Degree & Closeness & Betweenness & Eigenvector \\
\hline 30 & 6 & 0.006410 & 43.239745 & 0.022297 & 4 & 0.004167 & 0 & 0.000175 \\
\hline 31 & 6 & 0.005208 & 0 & 0.015571 & 33 & 0.006667 & 65.451659 & 0.994173 \\
\hline 32 & 14 & 0.006329 & 9.803968 & 0.085813 & 15 & 0.006173 & 2.528442 & 0.566290 \\
\hline 33 & 9 & 0.006211 & 2.023748 & 0.069773 & 32 & 0.006667 & 56.684520 & 0.977035 \\
\hline 34 & 5 & 0.005988 & 0 & 0.047021 & 8 & 0.007407 & 88.435017 & 0.325809 \\
\hline 35 & 4 & 0.005952 & 0 & 0.041150 & 9 & 0.007463 & 102.922842 & 0.362487 \\
\hline 36 & 6 & 0.006061 & 0.166667 & 0.050624 & 8 & 0.007407 & 88.435017 & 0.325809 \\
\hline 37 & 4 & 0.006897 & 50.281854 & 0.038455 & 31 & 0.006667 & 60.051453 & 0.937816 \\
\hline 38 & 6 & 0.006024 & 0.125000 & 0.055871 & 13 & 0.005128 & 0.499242 & 0.493058 \\
\hline 39 & 4 & 0.005988 & 0.142857 & 0.035553 & 9 & 0.005076 & 0.090909 & 0.361565 \\
\hline 40 & 7 & 0.007353 & 37.008510 & 0.054373 & 10 & 0.005076 & 0 & 0.431584 \\
\hline 41 & 12 & 0.006329 & 4.926264 & 0.081016 & 32 & 0.006667 & 65.139276 & 0.958958 \\
\hline 42 & 29 & 0.007092 & 122.239971 & 0.156257 & 10 & 0.005051 & 0 & 0.434185 \\
\hline 43 & 5 & 0.006024 & 0.125000 & 0.044005 & 10 & 0.005076 & 0 & 0.429916 \\
\hline 44 & 7 & 0.007407 & 47.600346 & 0.057677 & 31 & 0.006667 & 55.516976 & 0.952541 \\
\hline 45 & 13 & 0.006173 & 3.894048 & 0.088129 & 14 & 0.005155 & 0.797594 & 0.530931 \\
\hline 46 & 15 & 0.006494 & 15.461847 & 0.089836 & 10 & 0.005102 & 0.176923 & 0.402909 \\
\hline 47 & 6 & 0.006135 & 1.723214 & 0.045117 & 9 & 0.007463 & 102.922842 & 0.362487 \\
\hline 48 & 6 & 0.006135 & 0.642857 & 0.048636 & 10 & 0.007519 & 136.849264 & 0.389300 \\
\hline 49 & 5 & 0.006024 & 0 & 0.046627 & 8 & 0.007407 & 88.435017 & 0.325809 \\
\hline 50 & 3 & 0.006849 & 36.711471 & 0.031818 & 10 & 0.005102 & 0.190909 & 0.388582 \\
\hline 51 & 5 & 0.006024 & 0.333333 & 0.043262 & 32 & 0.006667 & 64.917831 & 0.959143 \\
\hline 52 & 29 & 0.008696 & 562.469505 & 0.154471 & 24 & 0.006329 & 15.761499 & 0.774612 \\
\hline 53 & 8 & 0.006623 & 30.620420 & 0.054845 & 9 & 0.005076 & 0.090909 & 0.363278 \\
\hline 54 & 11 & 0.006369 & 9.067685 & 0.080765 & 10 & 0.005076 & 0 & 0.419513 \\
\hline 55 & 7 & 0.006173 & 1.067430 & 0.058609 & 33 & 0.006667 & 61.268525 & 1 \\
\hline 56 & 7 & 0.006061 & 0.222222 & 0.061111 & 8 & 0.004425 & 0 & 0.000375 \\
\hline Mean & 9.34 & 0.006179 & 52.529119 & 0.195115 & 12.16 & 0.005753 & 43.832143 & 0.259449 \\
\hline
\end{tabular}

Table 7. Changes in centality analysis variables of middle school students before and after the application of the program $(n=56)$

\begin{tabular}{|c|c|c|c|}
\hline \multirow{2}{*}{ Variable } & Pre & Post & \multirow{2}{*}{$\dagger$} \\
\hline & Mean (SD) & Mean (SD) & \\
\hline Degree & $9.34(5.779)$ & $12.16(9.069)$ & $-2.088^{*}$ \\
\hline Closeness & $0.0062(0.0009)$ & $0.0058(0.0010)$ & $2.407^{*}$ \\
\hline Betweenness & $52.5291(125.3904)$ & $43.8321(51.8918)$ & 0.485 \\
\hline Eigenvector & $0.1951(0.2630)$ & $0.2594(0.3382)$ & 0.958 \\
\hline
\end{tabular}

${ }^{*} \mathrm{p}<0.05$. Betweenness: betweenness centrality, Closeness: closeness centrality, Degree: degree centrality, Eigenvector: eigenvector centrality

and female students $\mathrm{p}=0.00011)$. There was a significant change in the closeness centrality ( $\mathrm{p}=0.001$ ) of male students in the statistics showing the centrality of social network analysis, and there was also a significant change in the closeness centrality ( $\mathrm{p}=0.001$ ) of female students (Table 8 ). However, if male students and female students point at each other, we cannot say that it reflects the whole group when we look at the relationships between men and women. However, there was a significant change in the degree of peer relationships within the groups of male students and female students before and after application of the social skills training program.

As for changes in peer relationships before and after application of the social skills training program, peer relationships may change due to the timing difference at the beginning of the term and seven weeks later. This is because we cannot exclude the possibility that peer relationships have changed due to the increased intimacy during the 7-week class life.

According to the changes in the peer relationship conducted in the first and second graders of middle school in Seoul in 2016 (2326 male students, 2302 female students), the second-year students shared a narrow and close relationship and their number of friends decreased and became more tight as time passed compared with first-year students. Since the beginning of the term is the period of forming a peer relationship, peer relationships are expected to slow down and 


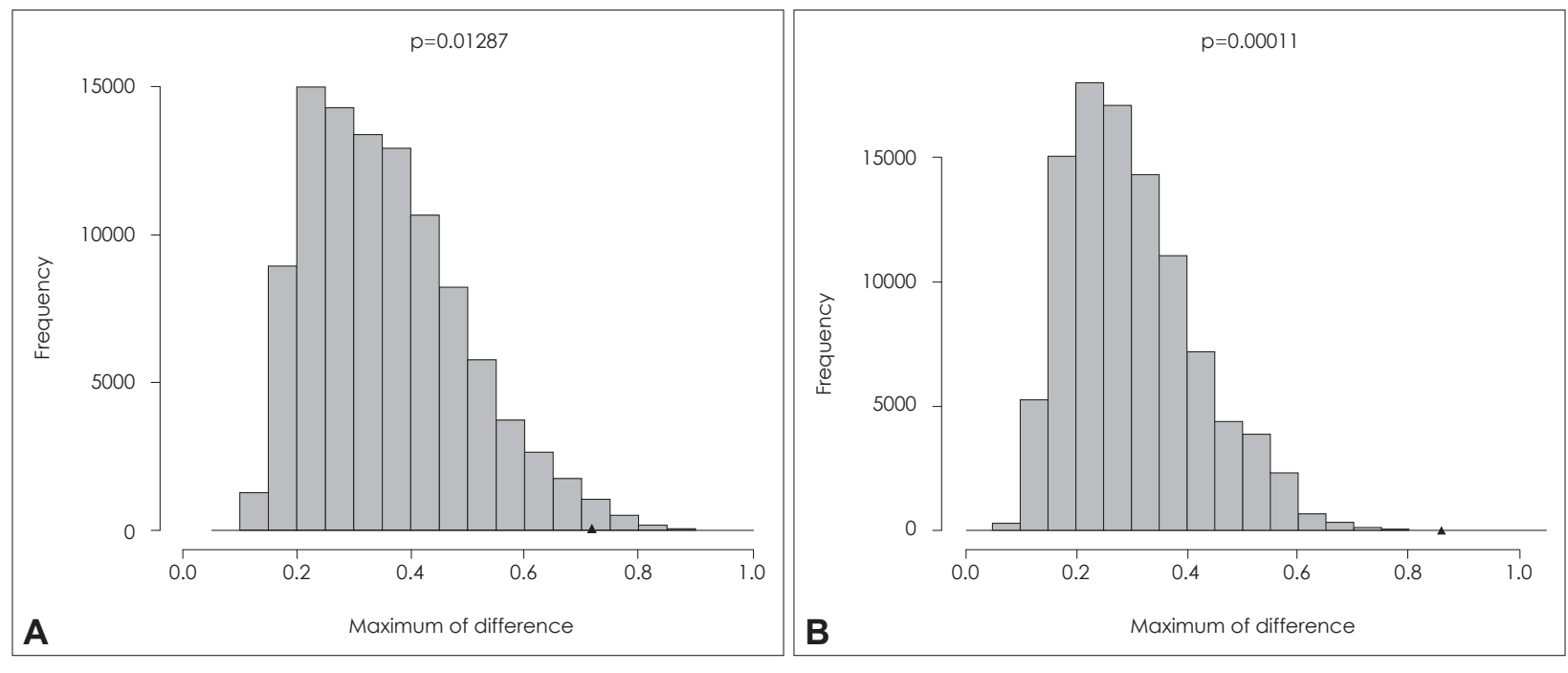

Fig. 7. Reference distributions of test statistics based on boy and girl elementary and middle school students for the application of the program. The triangle indicates the test statistic based on the observed boy students $(A: n=47)$ and girl students (B: $n=43)$ data.

Table 8. Changes in centality analysis variables of boy and girl elementary and middle school students before and after the application of the program

\begin{tabular}{|c|c|c|c|c|c|c|}
\hline \multirow{3}{*}{ Variable } & \multicolumn{2}{|c|}{ Boy students $(n=47)$} & \multirow{3}{*}{$\dagger$} & \multicolumn{2}{|c|}{ Girl students $(n=43)$} & \multirow{3}{*}{$\dagger$} \\
\hline & Pre & Post & & Pre & Post & \\
\hline & Mean (SD) & Mean (SD) & & Mean (SD) & Mean (SD) & \\
\hline Degree & $4.36(2.933)$ & $4.45(3.195)$ & -0.165 & $6.15(4.081)$ & $7.08(5.738)$ & -1.100 \\
\hline Closeness & $0.0068(0.0002)$ & $0.0049(0.0002)$ & $7.262^{*}$ & $0.0049(0.0004)$ & $0.0052(0.0003)$ & $-4.413^{*}$ \\
\hline Betweenness & $12.74(38.7095)$ & $2.28(5.8892)$ & 1.973 & $3.49(8.4245)$ & $3.50(7.7184)$ & 0.0131 \\
\hline Eigenvector & $0.1776(0.2743)$ & $0.1117(0.2932)$ & 1.083 & $0.1376(0.2864)$ & $0.1942(0.3335)$ & -0.780 \\
\hline
\end{tabular}

${ }^{*} \mathrm{p}<0.01$. Betweenness: betweenness centrality, Closeness: closeness centrality, Degree: degree centrality, Eigenvector: eigenvector centrality

Table 9. Correlations for social network analysis variables

\begin{tabular}{lccc}
\hline \multicolumn{1}{c}{ Variables } & Degree & Closeness & Betweenness \\
\hline Closeness & $0.484^{*}$ & & \\
Betweenness & $0.479^{*}$ & $0.453^{*}$ & \\
Eigenvector & $0.424^{*}$ & -0.032 & 0.071
\end{tabular}

*p<0.01. Betweenness: betweenness centrality, Closeness: closeness centrality, Degree: degree centrality, Eigenvector: eigenvector centrality

improve naturally as time passes. However, dynamics of getting acquainted with each other and making new friends are very low as the semester passes, and active intervention by the school and teachers may be needed since peer relationships become more rigid as the grade goes up from grade 1 to grade $2 .{ }^{27)}$ Therefore, when looking at the transition in the peer relationships at the beginning and at the end of the term for middle school students in Seoul, students who do not have peer relationships are more likely to become more rigid toward the end of the semester.

It is suggested that school-based mental health promotion service can change peer relationships. This is because schoolbased mental health promotion service such as social skills training program can promote relationships among students. It is about gaining mental health information that they usually do not know, sharing it with their friends, and sharing a positive relationship with their peers. The results of this study suggest that providing this opportunity to elementary school students influences the formation of peer relationship. In this study, it is a good example that students who were not connected to the entire peer relationships were linked to the whole peer relationships after social skills training program.

Middle school students seem to have frequent peer relationships with peers in the same grade unlike elementary school students. In addition, when comparing before and after application of the social skills training program, there were cases where a previously mentioned student changed to another student, the number of students who have been previously mentioned has decreased or the number of students has increased, which seems to have unstable peer relationships. This suggests that school-based mental health promotion service may be an opportunity to enhance peer relationship but the opposite case should also be considered. An important developmental task is to establish self-identity 


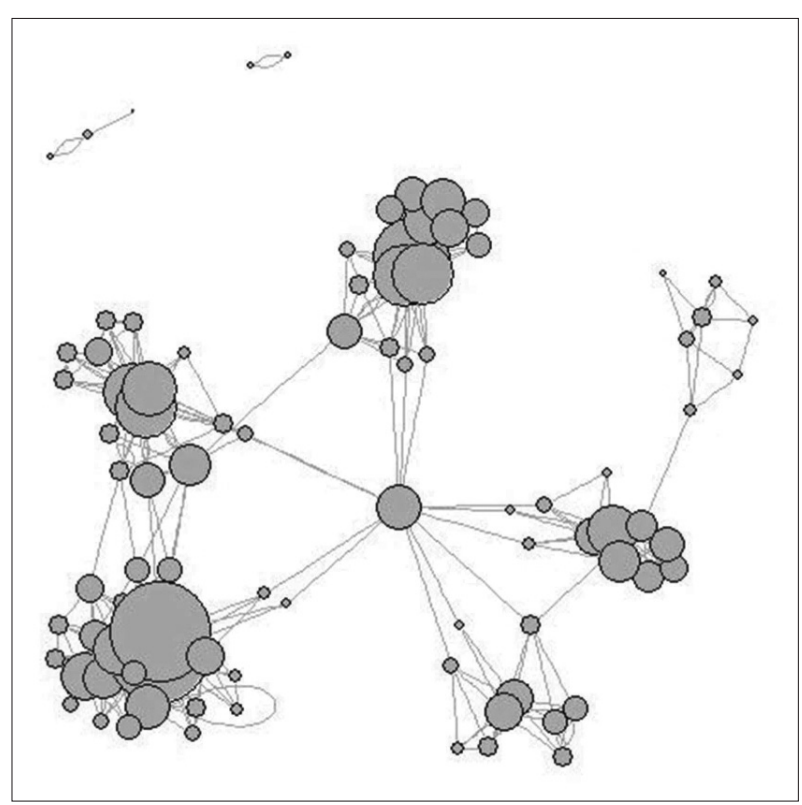

Fig. 8. Social network of elementary and middle school students before the application of the program $(n=90)$.

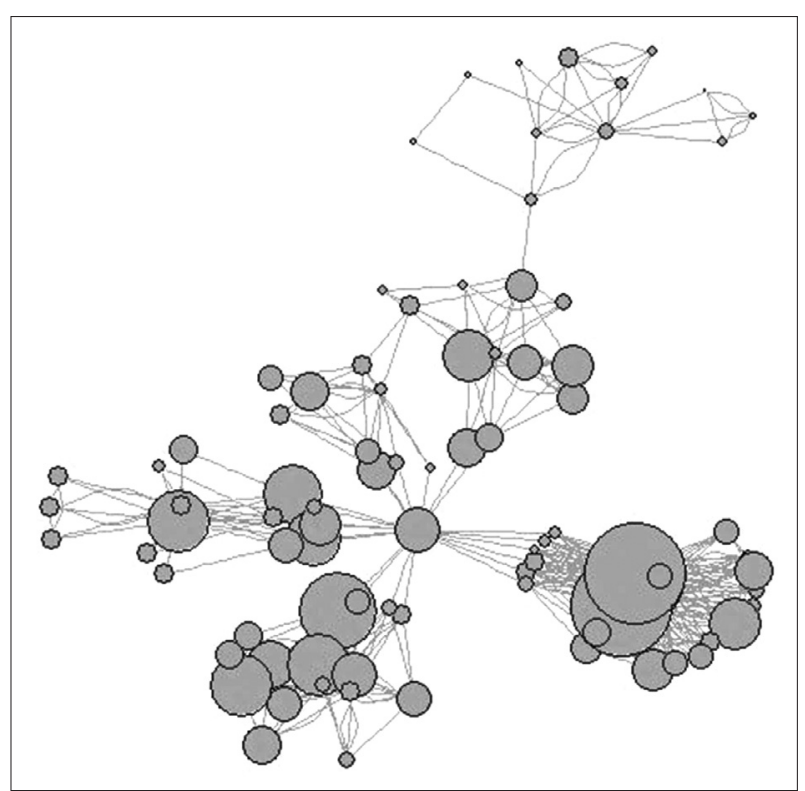

Fig. 9. Social network of elementary and middle school students after the application of the program $(n=90)$.

and to try various things at this time. Further, adolescents are greatly influenced by peer pressure because of the desire to get recognition from their peer group or to count on the standard of their peer group. Therefore, it is thought that it is necessary to provide customized age appropriate mental health promotion service at adolescence, an important time for establishing self-identity.

Although they are treated as anonymous in the study, it is meaningful to have a peer relationship as a methodology for discovering and paying attention to students who have few- er relationships than other students. Examining and understanding these relationships with individuals and groups is seen as a contribution to the provision of better student mental health promotion services. Figs. 8 and 9 show a degree of peer relationship that includes both elementary school students and middle school students before and after application of the school-based social skills training program. Students who did not belong to the group before application of the program can be structurally observed connected with the whole group after application of the program and the degree of connection was increased after application of the program, compared with that before application of the program.

There are some limitations to this study. First, it cannot predict what kind of results will be seen compared with students in other areas because it is conducted among a small number of students in a certain area. In addition, considering the mental development and quality of peer relationships among school-age children, there is a need for further research to reflect the changes in the degree of peer relationships. Second, it is difficult to exclude the possibility that other uncontrolled variables affected the outcome because it was the result without the control group. Therefore, in order to confirm the effect of social skills training program on peer relationships, a comparative analysis with the same environment where the same time was spent without implementing any program is necessary. Third, it is necessary to follow up whether the same result is maintained in the future because it is the result based on the data created before and after application of the social skills training program.

Despite these limitations, we can find the significance of this study in that the study examines the impact of social skills training program on peer relationships and confirms that school-based mental health promotion program can bring about significant changes in peer relationships.

\section{CONCLUSION}

It were able to examine that school-based social skills training program increases the connectivity through the peer relationships and brings about a structural change in the peer relationship. However, research on the long-term effects of detailed program contents and education is still insufficient. This study is a preliminary study that examines the effect of social skills training program on peer relationships, and it is necessary to confirm that social skills training program as a school-based mental health promotion service can positively contribute to peer relationships through additional studies.

\section{Conflicts of Interest}

The authors have no financial conflicts of interest. 


\section{REFERENCES}

1) Kim HJ, Roh JU. A study on the change of youth peer network - focusing on the life competency. J Future Oriented Youth Soc 2010;7: 87-109.

2) Song YM, Lee HC. The determinants of friendship among adolescent in Korea. J Korean Teach Educ 2011;28:91-112.

3) EGifford-Smitha ME, Brownell CA. Childhood peer relationships: social acceptance, friendships, and peer networks. J Sch Psychol 2003;41:235-284.

4) Birch SH, Ladd GW. Children's interpersonal behaviors and the teacher-child relationship. Dev Psychol 1998;34:934-946.

5) Rutter M. School effects on pupils progress: research findings and policy implications. Child Dev 1983;54:1-29.

6) Hartup WW. Social relationships and their developmental significance. Am Psychol 1989;44:120-126.

7) Hartup WW. The company they keep: friendships and their developmental significance. Child Dev 1996;67:1-13

8) Demaray MK, Malecki CK, Davidson LM, Hodgson KK, Rebus PJ. The relationship between social support and student adjustment: a longitudinal analysis. Psychol Sch 2005;42:691-706.

9) Kim HJ. Determinants of human relationships: a network analysis. Korean J Commun Stud 2000;8:58-77.

10) Bahn GH. A trial application of evidence-based and school-based community program for enhancement of mental health in school children. Seoul: National Center for Mental Health;2010.

11) Sim SY, Park SH, Lee MH, Lee MS. A study on application of schoolbased mental health improvement programs: focusing on sociality improvement programs. Ment Health 2015;6:41-47.

12) Cho NA. A theoretical review of participation in youth group activities and its potential as social capital. J Future Oriented Youth Soc 2008;5:177-198.

13) Bae EK. The changes of Korean public mental health services for children and adolescents - challenges for mental health promotion. Ment Health Soc Work 2015;43:283-312.

14) Hendren R, Weisen RB, Orley J. Mental health programmes in schools. Geneva: World Health Organization;1994.
15) Lee HM. Effects of the emotion regulation competence enhancement program on elementary school students' aggression and peer relations [dissertation]. Gwangju: Chonnam National Univ.;2013.

16) Kim SY. The effect of a emotion regulation program on aggression of elementary school students with aggression problems [dissertation]. Daegu: Kyungpook National Univ.;2008.

17) Kang YH. The effect of emotional intelligence strengthening program on emotional ability and peer relationship of primary school students [dissertation]. Seoul: Hongik Univ.;2008.

18) Lee DY, Roh EM, Kim IY, Ko GN, Choi JW, Lee YR, et al. Schoolbased short term mental health awareness and school bullying prevention programs: preliminary report. J Korean Acad Child Adolesc Psychiatry 2014;25:196-202.

19) Kim MS, Shin JU, Lee YR, Lee YW, Jung KA, Jung DN, et al. Effects of School-Based Social Skills Training Program on Alexithymic Tendency: preliminary study. J Korean Acad Child Adolesc Psychiatry 2016;27:216-225

20) Kim KM, Lee JA, Yeom YS. Characteristics of social network and suicide impulse by school violence experiences in Korean adolescents. Korean J Sociol 2013;6:707-718.

21) Woo DG. Group counseling program manual. Daegu: Daegu Metropolitan Office of Education;2012. p.128-169.

22) Kim YH, Kim YJ. Social Network Analysis. Seoul: Pakyoung; 2016.

23) Moreno JL. Who shall survive? A new approach to the problem of human interrelations. Washington, DC: Nervous and Mental disease Publishing; 1934.

24) Korea Data Agency. The guide for advanced data analytics professional. Seoul: Korea Data Agency;2016.

25) Kim SK. Social Network Analysis (SNA) and industrial engineering. ie Magazine 2011;18:24-32.

26) Winkley L. Emotional problems in children and young people. London: Cassell;1996.

27) Song SK. Social network analysis report of middle school students in Seoul. Seoul: Seoul Metropolitan Office of Education;2016. 